\title{
New Multiplier/Divider Using a Single Cdba
}

\author{
J. K. Pathak ${ }^{1}$, A. K. Singh ${ }^{2}$, Raj Senani, \\ ${ }^{1}$ Department of Electronics and Communication Engineering, Echelon Institute of Technology, Faridabad, India \\ ${ }^{2}$ Department of Electronics and Communication Engineering, Faculty of Engineering and Technology, HRCT Group of Institutions, \\ Morta, Ghaziabad, India \\ ${ }^{3}$ Division of Electronics and Communication Engineering, Netaji Subhas Institute of Technology, Sector 3, Dwarka, New Delhi, India \\ *Corresponding author: senani@ieee.org
}

Received September 29, 2013; Revised November 28, 2013; Accepted May 09, 2014

\begin{abstract}
A new multiplier-divider circuit using a single Current Differencing Buffered Amplifier (CDBA) and only six MOSFETs has been presented. The proposed circuit has the advantage of simultaneously realizing a multiplier and divider without changing the circuit topology. The basic functions of the proposed circuit have been verified through PSPICE simulations using a CMOS CDBA and NMOS transistors with process parameters of 0.35 $\mu \mathrm{m}$ CMOS technology and some application results of the proposed cell in various modes of operation have been included.
\end{abstract}

Keywords: analog multipliers, Analog Dividers, Current differencing buffered amplifiers, Analog Integrated Circuits, Analog Signal Processing, CMOS Circuits

Cite This Article: J. K. Pathak, A. K. Singh, and Raj Senani, "New Multiplier/Divider Using a Single Cdba.” American Journal of Electrical and Electronic Engineering, vol. 2, no. 3 (2014): 98-102. doi: 10.12691/ajeee-2-3-7.

\section{Introduction}

The Current differencing buffered amplifier (CDBA) [1] and its current-controlled version have received significant attention in literature as they have been shown to offer a lot of flexibility and versatility in analog circuit design, for instance, see $[2,3,4,15,16,17,18]$ and the references cited therein. Several bipolar and CMOS implementations of the CDBA have also been advanced over the years such as those in [1,2,3,4] and [16-22].

The circuit symbol of the CDBA is shown in Figure 1. A CDBA is a four terminal building block which is characterized by the terminal equations

$$
V_{p}=V_{n}=0, i_{z}=i_{p}-i_{n}, V_{w}=V_{z}
$$

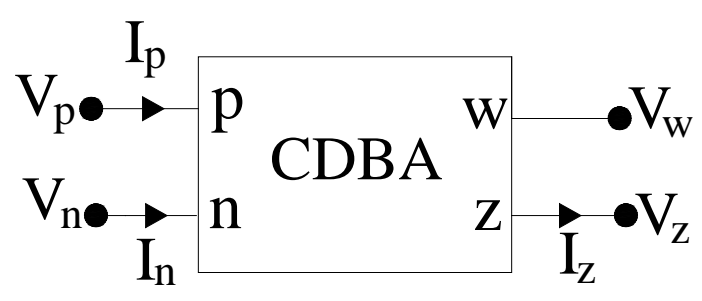

Figure 1. Symbolic notation of the CDBA

Various researchers have proposed analog multiplier and/or divider circuits in the past using a variety of active building blocks such as Current Controlled Current Conveyors (CCCII) [5,7], second generation Current Conveyors (CCII) [6], operational trans-conductance amplifiers (OTA) [8], current differencing trans conductance amplifiers (CDTA) [9], operational amplifiers [10,11,12,19], operational trans-resistance amplifier (OTRA) [13], current feedback operational amplifiers (CFOA) [14], current controllable current conveyor trans conductance amplifier (CC-CCTA) [20], dual-X second-generation current conveyors (DXCCIIs) [21] and current controlled current-differencing trans-conductance amplifiers (CCCDTA) [22].

These multiplier/divider circuits, however, suffer from one or other problems. For example, the four quadrant multiplier and two quadrant divider reported in [5] has the disadvantage of employing two active elements (CCCII+s) elements are the performance of the circuit is temperaturesensitive. Similarly, the four quadrant analog multiplier presented in [6] also needs two active elements (CCIIs). On the other hand, the current mode (CM) multiplier proposed in [7] based on bipolar CCCII+ uses one active element and a current controlled ground resistor, requires current-matching for successful operation as multiplier, is temperature-sensitive, has non-differential current inputs and suffers from the effects of the parasitic impedances of the CCCII+. The OTA-based CM analog multiplierdivider reported in [8] uses too many active elements (three OTAs). The CM analog multiplier and divider introduced in [9] use two CC-CDTAs but have nondifferential inputs. The circuits of $[10,11]$ realize a multiplier/divider using a single op-amp and eight MOSFETs but the circuit employs both positive and negative feedback thereby leading to a condition for the stability while that of [12] although reduces the number of MOSFETs to six but needs two op-amps to realize multiplier/divider. Furthermore, as these circuits [10,11,12] are based on op-amps, their operation is limited by the well-known limitations of the op-amps. Using a single OTRA and eight MOS transistors, an analog multiplier 
was reported in [13] but this circuit has the limitation of allowing only non-differential inputs. In [14], Liu reported a circuit using only four MOSFETs and two CFOAs ${ }^{1}$, but the circuit therein realizes only a divider. In [19], Riewruja and Rerkratn reported a four-quadrant multiplier using opamps but the circuit requires as many as five op-amps and eleven resistors and is hence, not economical. Woratraijariya, Mano, Jaikla, and Maneewan in [20] reported a CM four quadrant divider, using a single CCCCTA but the circuit can perform only the operation of a divider. Kumngern [21] presented a four-quadrant multiplier based on two DXCCIIs but the circuit can perform only multiplication. Siripruchyanun and Jaikla [22] introduced a CM analog multiplier/divider based on CC-CDTA but circuit can operate as multiplier/divider for only two quadrants.

On the other hand, among the multipliers/dividers employing CDBAs known earlier, the circuit of [15] employs a single CDBA along with only four MOSFETs but realizes only a multiplier. Siripruchyanun [16] presented a CM analog multiplier and divider using two CC-CDBA [17] but their circuit provides only two quadrant operation as a multiplier. Jaikla and Siripruchyanun in [18] also reported a CM analog multiplier and a divider but their circuits require three and two CC-CDBAs respectively. Another significant drawback of the circuits of $[17,18]$ is that different circuit topologies are required for multiplier and divider operations.

In contrast to the above mentioned circuits, this paper proposes a new CDBA-based circuit which uses only a single CDBA along with only six MOSFETs but offers the significant advantages of (i) simultaneous realisability of a multiplier as well as a divider from the same configuration and (ii) independence of the output of the configuration from the aspect ratios of the MOSFETs if all of them are assumed to be matched (on the other hand, different aspect ratios of input and output MOS transistors can be used to have a desired gain factor). The workability of the proposed circuit, in its various application modes, has been verified by SPICE simulations employing the CMOS CDBA architecture of [2] using $0.35 \mu \mathrm{m}$ CMOS technology and some sample application results have been presented.

\section{The Proposed Multiplier/Divider Cell}

Figure 2 shows the proposed multiplier/divider cell. Considering n-channel MOS transistors operating in triode region and assuming the aspect ratios of $\mathrm{M}_{1}$ to $\mathrm{M}_{4}$ as $\left(W_{i}\right.$ $\left./ L_{i}\right)$ and that of $\mathrm{M}_{5}$ and $\mathrm{M}_{6}$ as $\left(W_{o} / L_{o}\right)$, and using the characterizing equation (1) of the CDBA, the interrelationship between the drain currents of the various MOSFETs can be written as

$$
I_{d_{1}}+I_{d_{2}}+I_{d_{5}}-I_{d_{3}}-I_{d_{4}}=I_{d_{6}}
$$

Using drain current equation of all the MOSFETs operating in triode region in terms of $\mathrm{V}_{\mathrm{gs}}$ and $\mathrm{V}_{\mathrm{ds}}$, from (2), the voltage output of the circuit is found to be

\footnotetext{
${ }^{1}$ A closer look at the circuit of Fig.3 of [14] reveals that the composite connection of the two CFOAs therein is exactly configured as a CDBA! Hence, the two-CFOA-based analog divider of Fig.3 of [14] can also be considered to be single-CDBA-four-MOSFETs-based analog divider.
}

$$
V_{o}=\frac{\left(W_{i} / L_{i}\right)}{\left(W_{o} / L_{o}\right)} \frac{\Delta X \Delta Y}{\Delta Z}
$$

where $\Delta X=\left(X_{1}-X_{2}\right), \quad \Delta Y=\left(Y_{1}-Y_{2}\right)$ and $\Delta Z=\left(Z_{1}-Z_{2}\right)$. Thus, like the circuits of $[5,6]$, the proposed circuit can perform the computation of $(\Delta X \Delta Y / \Delta Z)$ where all the signals are differential input voltages and if aspect ratios of all MOS transistors are taken to be same, the output voltage becomes independent of the parameters of the MOS transistors.

In order to keep operation of all the MOS transistors in the linear region one requires:

For $\mathrm{M}_{1}$ to $\mathrm{M}_{4}$

$$
Y_{1}, Y_{2} \leq \min \left[\left(X_{1}-V_{T}\right),\left(X_{2}-V_{T}\right)\right]
$$

For $\mathrm{M}_{5}$ to $\mathrm{M}_{6}$ :

$$
V_{o} \leq \min \left[\left(Z_{1}-V_{T}\right),\left(Z_{2}-V\right)_{T}\right]
$$

where $\mathrm{V}_{\mathrm{T}}$ is the threshold voltage of the MOS transistors.

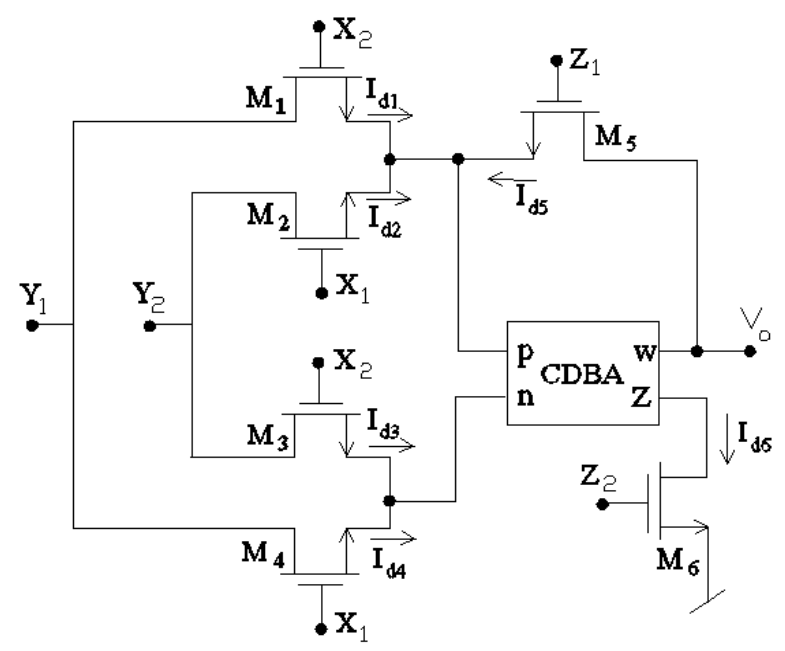

Figure 2. The proposed Multiplier/Divider cell

\section{SPICE Simulation Results}

To verify the workability of the proposed configuration, a number of its applications have been checked through SPICE simulations using the CMOS CDBA of [2] biased with $\pm 5 \mathrm{~V}$ DC supply while using MOS transistors with $0.35 \mu \mathrm{m}$ CMOS process parameters.

\subsection{Analog Divider}

For checking the divider operation, input signals were applied at $\mathrm{Y}$ and $\mathrm{Z}$ terminals and the control voltages were applied at $\mathrm{X}$ terminal of the MOSFETs. Taking $\mathrm{Y}_{1}=\mathrm{Y}_{2}=$ $\mathrm{y}, \mathrm{X}_{1}=\mathrm{Vc}_{1}$ and $\mathrm{X}_{2}=\mathrm{Vc}_{2}, \mathrm{Z}_{1}=(\mathrm{Z}+\mathrm{z})$ and $\mathrm{Z}_{2}=(\mathrm{Z}-\mathrm{z})$, where $Z$ is the $D C$ bias at gate terminal of $M_{5}$ to $M_{6}$ and $\mathrm{Vc}_{1}, \mathrm{VC}_{2}$ are DC control voltages, we obtain output voltage as

$$
V_{o}=\left(V_{c 2}-V_{c 1}\right) \frac{\left(W_{i} / L_{i}\right)}{\left(W_{o} / L_{o}\right)} \frac{y}{z}
$$


The conditions required to keep operation of the MOS transistors in the linear region are given by

For $\mathrm{M}_{1}$ to $\mathrm{M}_{4}$ :

$$
y \leq \min \left[\left(V_{c 1}-V_{T}\right),\left(V_{c 2}-V_{T}\right)\right]
$$

For $\mathrm{M}_{5}$ to $\mathrm{M}_{6}$ :

$$
Z+V_{o} \leq\left(Z-V_{T}\right)
$$

In SPICE simulations of the divider circuit, $\mathrm{V}_{\mathrm{c} 1}$ and $\mathrm{V}_{\mathrm{c} 2}$ were kept at $5.0 \mathrm{~V}$ and $4.95 \mathrm{~V}$ respectively while $\mathrm{Z}$ was kept at $4.5 \mathrm{~V}$. The input signal $\mathrm{z}$ was varied from $-2 \mathrm{~V}$ to $0.6 \mathrm{~V}$ and y signal was varied from $-0.2 \mathrm{~V}$ to $0.2 \mathrm{~V}$ in steps of $0.1 \mathrm{~V}$. With all MOSFETs having same aspect ratios, the simulation results and theoretical results are shown in Figure 3 which are found to be closely matching with the theoretical ones.

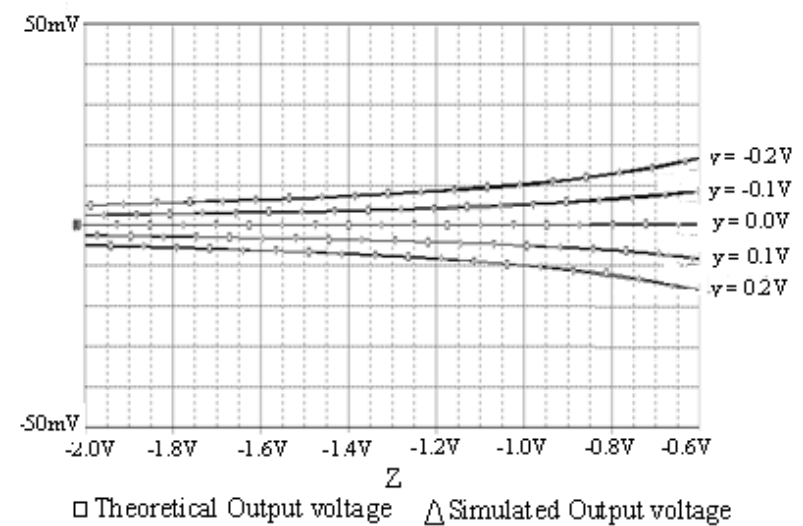

Figure 3. DC transfer characteristics of the proposed configuration used as a divider

\subsection{Analog Multiplier}

In this case, the input signals are applied at the $\mathrm{X}$ and $\mathrm{Y}$ terminals. Let $\mathrm{Y}_{1}=-\mathrm{Y}_{2}=-\mathrm{y}, \mathrm{X}_{1}=(\mathrm{X}+\mathrm{x})$ and $\mathrm{X}_{2}=(\mathrm{X}-\mathrm{x})$, $\mathrm{Z}_{1}=\mathrm{Vc}_{1}$ and $\mathrm{Z}_{2}=\mathrm{Vc}_{2}$, where $\mathrm{X}$ is the $\mathrm{DC}$ bias at gate terminal of $\mathrm{M}_{1}$ to $\mathrm{M}_{4}$ and $\mathrm{Vc}_{1}, \mathrm{Vc} 2$ are $\mathrm{DC}$ control voltages. Using these signals and control voltage, we obtain the output voltage of the circuit as

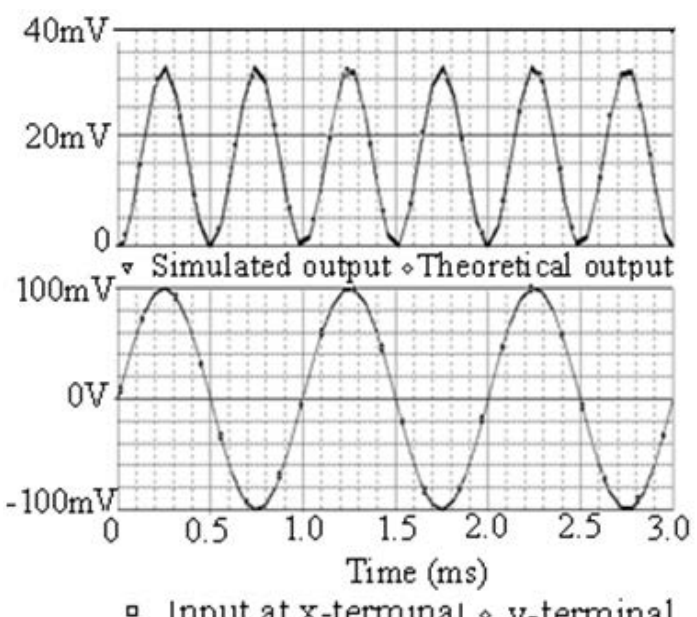

(a)

Figure 5. Simulation results of the proposed cell as a squarer (a) time response (b) frequency spectrum

$$
V_{o}=\frac{4\left(W_{i} / L_{i}\right)}{\left(W_{o} / L_{o}\right)} \frac{x y}{\left(V_{c 2}-V_{c 1}\right)}
$$

The condition required to keep operation of the MOS transistors in the linear region is given by

For $\mathrm{M}_{1}$ to $\mathrm{M}_{4}$ :

$$
(x+y) \leq\left(X-V_{T}\right)
$$

The widths and lengths of $\mathrm{M}_{1}$ to $\mathrm{M}_{6}$ were taken as 2.8 $\mu \mathrm{m}$ and $0.35 \mu \mathrm{m}$ respectively; $\mathrm{X}$ was kept at $4.0 \mathrm{~V}$ while $\mathrm{V}_{\mathrm{z} 1}$ and $\mathrm{V}_{\mathrm{z} 2}$ were kept at $3.75 \mathrm{~V}$ and $5 \mathrm{~V}$ respectively. The $\mathrm{x}$ input signal was varied from $-0.23 \mathrm{~V}$ to $0.23 \mathrm{~V}$ and y signal was varied from $-180 \mathrm{mV}$ to $180 \mathrm{mV}$ in step of $90 \mathrm{mV}$. Figure 4 shows the simulation results which are seen to be in good agreement with the theoretical ones.

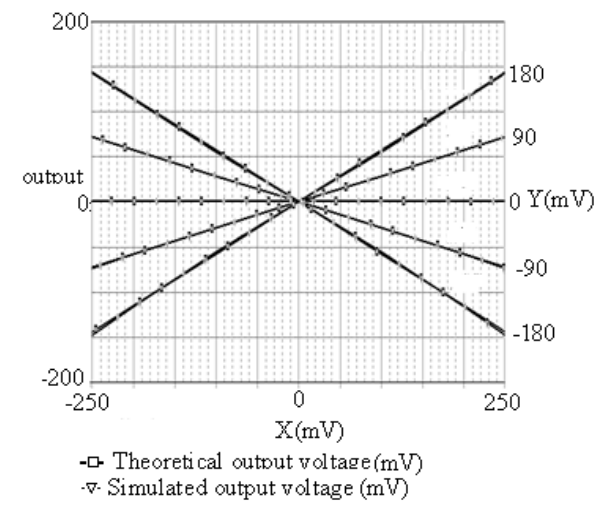

Figure 4. DC transfer characteristics of the proposed configuration as a multiplier

\subsection{Squarer}

For using the circuit as a squarer, $\mathrm{X}$ was kept at $4.5 \mathrm{~V}$ while $\mathrm{V}_{\mathrm{z} 1}$ and $\mathrm{V}_{\mathrm{z} 2}$ were kept at $3.75 \mathrm{~V}$ and $5 \mathrm{~V}$ respectively. The inputs $\mathrm{x}$ and $\mathrm{y}$ were both taken as sinusoidal signals of $1 \mathrm{KHz}$, zero avg., 200mVpp. Figure 5 shows the simulation results of the proposed configuration as a squarer.
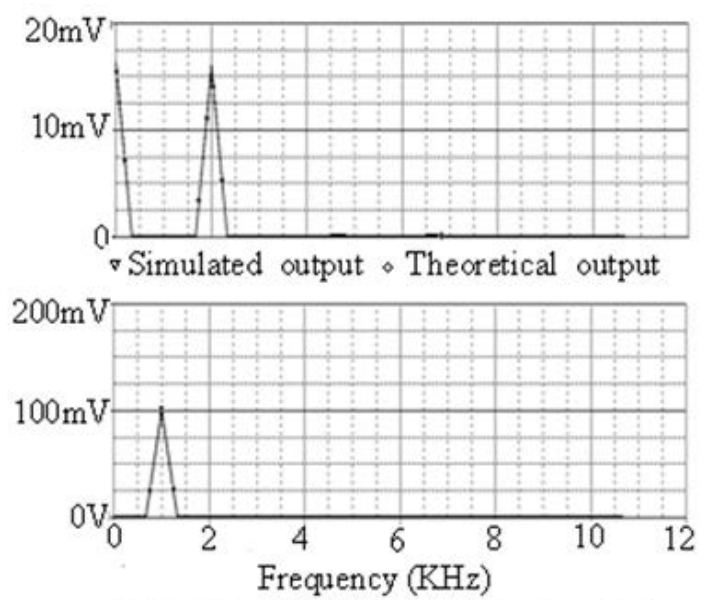

anput at $\mathrm{x}$-terminal $\diamond$ Input at $\mathrm{y}$-terminal

(b)

\subsection{Modulator}

To verify the operation of the proposed configuration as a modulator, $\mathrm{X}$ was kept at $4.5 \mathrm{~V}$ while $\mathrm{V}_{\mathrm{z} 1}$ and $\mathrm{V}_{\mathrm{z} 2}$ were kept at $3.75 \mathrm{~V}$ and $5 \mathrm{~V}$ respectively. The input $\mathrm{x}$ was 
sinusoidal signal of $1 \mathrm{KHz}$, zero avg., 200mVpp while y was taken as a sinusoidal signal of $10 \mathrm{KHz}$, zero avg., $200 \mathrm{mVpp}$. Figure 6 shows the simulation results of the circuit as a modulator.

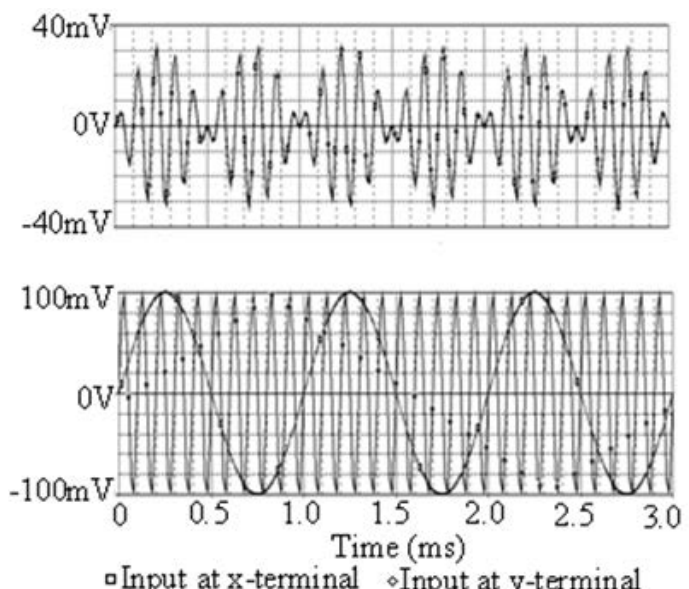

(a)
The SPICE simulation results of Figure 3-Figure 6, thus, establish the workability of the proposed configuration in its various modes of operation.

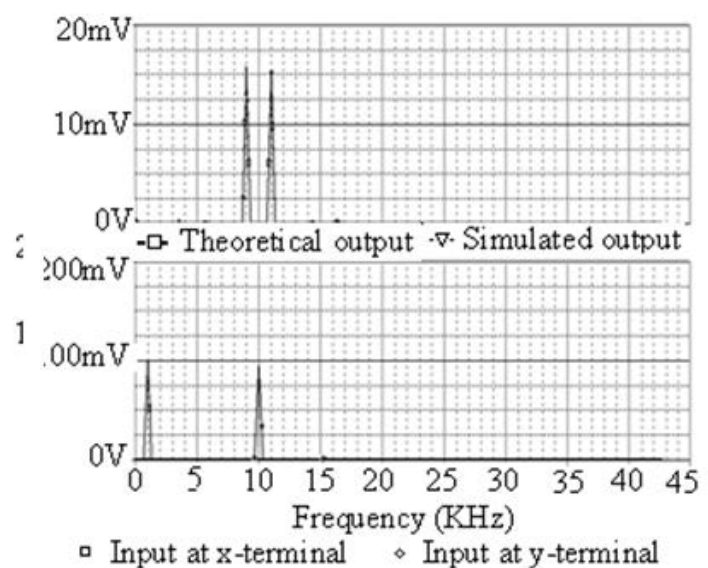

(b)

Figure 6. Simulation results of the proposed configuration as a squarer (a) time response (b) frequency spectrum

\subsection{Frequency Characteristics of the Proposed Configuration}

In this case, the input $\mathrm{X}$ was kept at $4 \mathrm{~V}$ while $\mathrm{V}_{\mathrm{z} 1}$ and $\mathrm{V}_{\mathrm{z} 2}$ were kept at $3.75 \mathrm{~V}$ and $5 \mathrm{~V}$ respectively. The input $\mathrm{x}$ was taken as a sinusoidal signal of amplitude $1 \mathrm{mV}$ of varying frequency and y was taken as a DC signal of $0.1 \mathrm{~V}$. Figure 7 shows the frequency response of the proposed configuration obtained through SPICE simulations which is seen to exhibit a bandwidth of around $82.3 \mathrm{MHz}$.

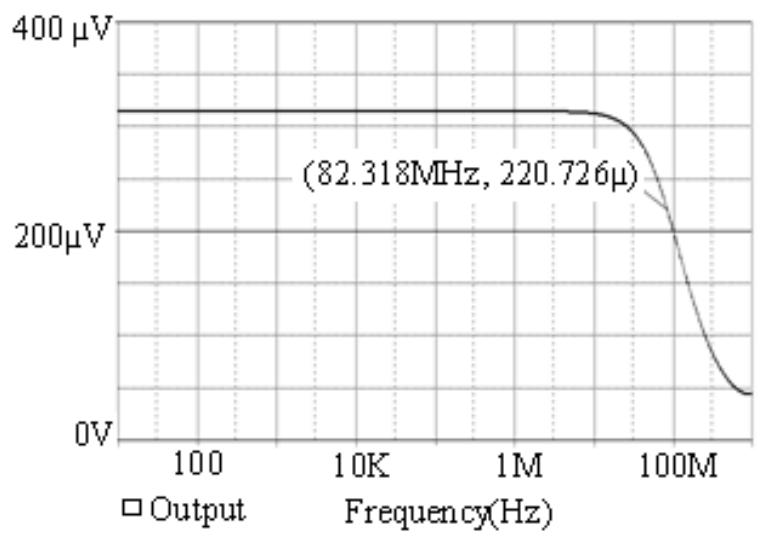

Figure 7. Frequency response of the proposed Multiplier/Divider cell obtained through SPICE simulations

\section{Concluding Remarks}

A new multiplier/divider cell based on a single CDBA is presented. While previously known single-CDBA-fourMOSFETs-based circuits can realize only a multiplier as in [15] or only a divider as in [14] (with the two CFOAs employed therein configured exactly equivalent to a CDBA as mentioned in footnote 1 ), the presented singleCDBA-based configuration uses six MOSFETs but has the advantage of realizing both multiplier and divider functions simultaneously. SPICE simulation results based on CMOS CDBA and MOS transistors in 0.35um CMOS technology have confirmed the workability of the proposed configuration in its various modes of operation. The layout of the proposed cell using CMOS CDBA architecture from [2] has shown the chip area of the circuit as $0.015 \mathrm{~mm}^{2}$ (layout area without pads).

\section{Acknowledgement}

This work was performed at Analog Signal Processing Research Lab and Circuit Simulation Lab of NSIT, New Delhi. Thanks are due to Ankur Sangal of Coreel Technology India Pvt. Ltd. for his assistance with the layout design.

\section{References}

[1] Acar, C. and Ozoguz, S, “A new versatile building block: Current differencing buffered amplifier suitable for analog signal processing filters,” Microelectronics journal, 30. 157-160.1999.

[2] Acar, C. and Sedef, H, "Realization of nth order current transfer function using current differencing buffered amplifiers," International of Electronics, 90(4). 277-283. 2003.

[3] Tangsrirat, W., Klahan, K., Dunmawipata, T. and Surakampontorn, W., "Low-voltage NMOS-based current differencing buffered amplifier and its application to current-mode ladder filter design," International Journal of Electronics, 93(11). 777-791.2006.

[4] D. Biolek, D., Bajer, J., Biolkova, V., Kolka, Z. and Kubrick, M, "Z-copy-controlled Gain-current differencing buffered amplifier and its applications,” International Journal of Circuit Theory and Applications, 39.257-274. 2010.

[5] Abuelma'atti, M.T. and Al- Qahtani, M.A, “A current- mode current-controlled current-conveyor based analogue multiplier/ divider,” International Journal of Electronics, 85(1). 71-77. 1998.

[6] Premont, C., Abouchi, N., Grisel, R. and Chante, J, “A BiCMOS current conveyor based four-quadrant analog multiplier,” Analog integrated circuits and signal processing, 19. 159-162. 1999.

[7] Yuce, E, "Design of simple current-mode multiplier topology using a single CCCII+," IEEE Transaction on Instrumentation and Measurement, 57(3). 631-637. 2008.

[8] Kaewdang, K., Fongsamut, C. and Surakampontorn, W, "A wide band current-mode OTA based. Analog multiplier-divider," Proceedings of the 2003 International Symposium on Circuits and Systems, 1.349-352. 2003. 
[9] Tangsrirat, W., Pukkalanun, T., Mongkolwai, P. and Surakampontorn, W, "Simple current-mode analog multiplier, divider, square-rooter and squarer based on CDTAs," International Journal of Electronics, 65 (3). 198-203. 2011.

[10] Khachab, N. I. and Ismail, M, "MOS multiplier/divider cell for analogue VLSI,” Electronics Letters, 25(23), 1550-1551. 1989.

[11] Khachab, N. I, “A nonlinear CMOS analog cell for VLSI signal and information processing,” IEEE Journal of Solid State Circuits, 26(11). 1689-1699. 1991.

[12] Ismail, M., Brannen, R., Takagi, S., Fujii, N., Khachab, N. I., Khan, R. and Asserud, O, "Configurable CMOS multiplier/divider circuits for analog VLSI,” Analog Integrated Circuits and Signal Processing, 5.219-234. 1994.

[13] Pandey, R., Pandey, N., Sriram, B. and Paul, S. K, "Single OTRA based analog multiplier and its applications," International Scholarly Research Network,” 2012, Article ID 890615, 7, 2012.

[14] Liu, S. I., and Chen, J. J, "Realization of analogue divider using current feedback amplifier,” IEE Proc. Circuits Devices System, 142(1). 45-48. 1995.

[15] Keskin, A. U, “A Four quadrant analog multiplier employing single CDBA,” Analog Integrated Circuits and Signal processing, 40. 99-101. 2004.

[16] Siripruchyanun, M, “A design of analog multiplier and divider using current controlled current differencing buffered amplifiers,”
Integrated Circuits, 2007. ISIC '07. International Symposium on Components, Circuits, Devices \& Systems, Engineered Materials, Dielectrics and Plasmas, 568-571. Sept. 2007.

[17] Maheshwari, S. and Khan, I. A, "Current controlled current differencing buffered amplifier: implementation and applications," Active and Passive Electronic components, 4. 219-227. Dec. 2004.

[18] Jaikla, W. and Siripruchyanun, M, "Novel current mode four quadrant multiplier/divider based on current controlled CDBAs (CCCDBAs),” The 2006 ECTI International Conference, 509-512. 2006.

[19] Riewruja, V. and Rerkratn, A, "Four-quadrant analogue multiplier using operational amplifier,” International Journal of Electronics, 98(4). 459-474. 2011.

[20] Woratraijariya, P., Mano, K., Jaikla, W. and Maneewan, S, "Current-mode 4 quadrant divider employing only single active element,” Electron Devices and Solid State Circuit (EDSSC), 2012 IEEE International Conference, 1-4. 2012.

[21] Kumngern, M, “A DXCCII-based Four-quadrant multiplier," Power Engineering and Optimization Conference (PEOCO), 2013 IEEE 7th International Conference, 738-741. 2013.

[22] Siripruchyanun, M. and Jaikla, W, "A current-mode analog multiplier/divider based on CCCDTA,” AEU - International Journal of Electronics and Communications, 62(3). 223-227. 2008. 